\title{
Coronary Artery Anomalies and Their Impact on the Feasibility of Percutaneous Pulmonary Valve Implantation
}

\author{
Anja Hanser ${ }^{1}\left[\right.$ ] Jörg Michel ${ }^{1} \cdot$ Andreas Hornung $^{1} \cdot$ Ludger Sieverding $^{1} \cdot$ Michael Hofbeck $^{1}$ (D)
}

Received: 23 April 2021 / Accepted: 23 July 2021 / Published online: 7 August 2021

(c) The Author(s) 2021

\begin{abstract}
One of the major obstacles preventing successful percutaneous pulmonary valve implantation (PPVI) is related to the close proximity of coronary artery branches to the expected landing zone. The aim of this study was to assess the frequency of coronary artery anomalies (CAAs) especially those associated with major coronary branches crossing the right ventricular outflow tract (RVOT) and to describe their relevance for the feasibility of percutaneous pulmonary valve implantation (PPVI). In our retrospective single-center study 90 patients were evaluated who underwent invasive testing for PPVI in our institution from $1 / 2010$ to $1 / 2020$. CAAs were identified in seven patients (8\%) associated with major branches crossing the RVOT due to origin of the left anterior descending (LAD) or a single coronary artery from the right aortic sinus. In 5/7 patients with CAAs balloon testing of the RVOT and selective coronary angiographies revealed a sufficiently large landing zone distal to the coronary artery branch. While unfavorable RVOT dimensions prevented PPVI in one, PPVI was performed successfully in the remaining four patients. The relatively short landing zone required application of the "folded" melody technique in two patients. All patients are doing well (mean follow-up 3 years). CAAs associated with major coronary branches crossing the RVOT can be expected in about $8 \%$ of patients who are potential candidates for PPVI. Since the LAD crossed the RVOT below the plane of the pulmonary valve successful distal implantation of the valve was possible in 4/7 patients. Therefore these coronary anomalies should not be considered as primary contraindications for PPVI.
\end{abstract}

Keywords Congenital heart disease $\cdot$ Percutaneous pulmonary valve implantation $\cdot$ Congenital coronary artery anomaly

$\begin{array}{ll}\begin{array}{l}\text { Abbreviations } \\ \text { CAA }\end{array} & \text { Coronary artery anomaly } \\ \text { CC } & \text { Coronary compression } \\ \text { CMR } & \text { Cardiac magnetic resonance } \\ \text { DORV } & \text { Double outlet right ventricle } \\ \text { ECG } & \text { Electrocardiogram } \\ \text { LAD } & \text { Left anterior descending coronary } \\ & \text { artery } \\ \text { LMC } & \text { Left main coronary } \\ \text { PA-VSD } & \text { Pulmonary atresia with ventricular } \\ & \text { septal defect } \\ \text { PPVI } & \text { Percutaneous pulmonary valve } \\ & \text { implantation }\end{array}$

Michael Hofbeck

michael.hofbeck@med.uni-tuebingen.de

1 Department of Pediatric Cardiology, University Children's Hospital Tuebingen, Hoppe-Seyler-Str. 1, 72076 Tuebingen, Germany

$\begin{array}{ll}\text { PTFE RV-PA conduit } & \begin{array}{l}\text { Polytetrafluoroethylene conduit } \\ \text { from right ventricle to pulmonary } \\ \text { artery }\end{array} \\ \text { RCA } & \begin{array}{l}\text { Right coronary artery } \\ \text { Right ventricular outflow tract }\end{array} \\ \text { RVOT } & \text { Tetralogy of Fallot }\end{array}$

\section{Introduction}

Percutaneous pulmonary valve implantation (PPVI) has found widespread acceptance in the postoperative revalvulation of the dysfunctional right ventricular outflow tract [1-4]. Major limitations for this procedure are coronary artery branches located in close proximity to the expected landing zone of the pulmonary valve resulting in the potential risk for coronary compression caused by radial tension from the balloon-expandable stent. Careful pre-interventional assessment of the coronary artery anatomy is therefore required in all patients selected for this procedure to avoid 
the catastrophic complication of coronary artery compression [5-7].

Specific attention is required in patients with coronary artery anomalies (CAAs). In patients with origin of the left anterior descending coronary artery (LAD) from the right aortic sinus the LAD crosses the right ventricular outflow tract (RVOT) in close proximity to a potential landing zone. This coronary anomaly is not uncommon in patients with tetralogy of Fallot, who represent a major percentage of potential candidates for PPVI [7-9]. The aim of this study was to assess the frequency and relevance of CAA impacting the feasibility of PPVI based on retrospective evaluation of all patients who underwent invasive testing in our institution.

\section{Materials and Methods}

Included in our retrospective study were all patients who underwent cardiac catheterization and balloon interrogation of the RVOT for possible PPVI in our center from 1/2010 to $1 / 2020$. It was the policy of our institution to offer testing for PPVI to all patients. Patients with known coronary artery anomalies in the presence of a conduit or RVOT of potentially treatable size were not excluded from invasive testing. Except for absence of informed consent of the patients or parents to the procedure there were no exclusion criteria. Prior to cardiac catheterization all patients underwent clinical examination, ECG, echocardiogram and chest X-ray. Data from cardiac MRI or CT were available in 66 and 15 patients, respectively. Invasive testing for PPVI included angiographies into the aortic root during simultaneous balloon inflation in the pulmonary outflow tract. In the majority of cases balloon interrogation was performed with Tyshak ${ }^{R}$ balloon catheters (NuMED Inc., Hopkinton, NY, USA) with a diameter of 25 or $30 \mathrm{~mm}$ and a length of $4-6 \mathrm{~cm}$. Due to residual uncertainty regarding the proximity of coronary arteries to the expected landing zone additional selective coronary angiographies were required in 25 patients. In 16 of these selective coronary angiographies were performed with simultaneous balloon inflation in the RVOT. Aortic root angiography in the laid-back technique was introduced in routine testing in 2013. We reviewed all angiographies performed in these patients for evaluation of the coronary artery anatomy and right ventricular outflow tract. Special attention was paid to detect anomalies of the coronary artery origin especially those resulting in major branches crossing the right ventricular outflow tract and their impact on the feasibility of PPVI. Unfavorable coronary artery anatomy was defined as either close proximity of a major coronary branch to the expected landing zone (especially in the context of restricted coronary artery mobility during balloon inflation) or compression and impeded flow in the coronary artery in the presence of the inflated balloon. Assessment of coronary artery anatomy included description of variants of origin and the site of close proximity or compression during balloon interrogation of the RVOT.

Statistical analysis was conducted using SPSS, version 27 (IBM Corp., Armonk, NY). This retrospective study was approved by the ethical committee of the University of Tuebingen (project number 307/2020BO2).

\section{Results}

Ninety patients underwent evaluation for possible PPVI. Mean age at the time of invasive testing was 22.8 years (median age 20.3 years, age range 6.9-67.7 years, SD 12.4 years). Mean weight was $57.8 \mathrm{~kg}$ (median weight $57.8 \mathrm{~kg}$, weight range $23-153 \mathrm{~kg}$, SD $23.5 \mathrm{~kg}$ ). Among our patients 60 were male and 30 were female. All patients had congenital heart disease associated with severely compromised pulmonary valve function (Table 1 ). At the time of evaluation 56 patients (62\%) had undergone previous surgery with implantation of a valved or nonvalved conduit between the subpulmonary ventricle and the pulmonary artery. One of these patients had two conduits from the subpulmonary ventricle to the pulmonary artery, and another patient had a conduit in addition to a stenotic but patent right ventricular outflow tract. Thirty-three patients (37\%) had undergone surgery of the pulmonary outflow including pulmonary commissurotomy, pulmonary valvectomy, or transannular patch enlargement. One patient had congenital pulmonary regurgitation without any preceding intervention or surgery.

Seventy-two patients (80\%) underwent successful implantation of pulmonary valves with one of three different balloon-expandable devices: Melody ${ }^{\mathrm{TM}}$ (Medtronic, Minneapolis, USA), SAPIEN XT, and SAPIEN 3 (both Edwards Lifesciences LLC, Irvine, USA). These included 69 Melody $^{\mathrm{TM}}$ valves in 67 patients. Two patients with dual connections of the subpulmonary ventricle to the pulmonary artery were treated by implantation of two Melody ${ }^{\mathrm{TM}}$ valves. One of these patients has been published before [10]. Three patients received SAPIEN XT valves and two patients SAPIEN 3 valves. Prestenting was performed in all patients using BIB Balloons (NuMED, Hopkinton, USA). Additional dilatation of the prestents-if required-was performed with Atlas ${ }^{\mathrm{R}}$ Gold high-pressure balloons (Bard Inc., Tempe, USA).

The option of PPVI was declined in 18/90 (20\%) of patients who underwent invasive testing (Table 2). This was exclusively due to coronary artery proximity or compression in 12 patients, while in another 4 patients an unfavorably large RVOT was associated with close proximity of a coronary artery branch to the fully expanded testing balloon. In the remaining two patients the landing zone exceeded 
Table 1 Diagnosis and anatomy of the RVOT in 90 patients with invasive PPVI testing
Table 2 Patients rejected for PPVI after invasive testing

\begin{tabular}{|c|c|c|c|c|}
\hline Diagnosis & $\begin{array}{l}\text { RVOT treated with homograft/ } \\
\text { contegra/valveless conduit/stented } \\
\text { valve }\end{array}$ & $\begin{array}{l}\text { Conduit-free } \\
\text { RVOT following } \\
\text { surgery }\end{array}$ & Native RVOT & Total \\
\hline $\mathrm{ToF}$ & $25(22)$ & $25(18)$ & & $50(40)$ \\
\hline PA-VSD & $14(12)$ & & & $14(12)$ \\
\hline DORV & $3(3)$ & $2(0)$ & & $5(3)$ \\
\hline TAC & $2(2)$ & & & $2(2)$ \\
\hline AOST s.p. Ross & $5(4)$ & & & $5(4)$ \\
\hline PST & $1(1)$ & $1(0)$ & $1(1)$ & $3(2)$ \\
\hline Complex TGA & $5(5)$ & & & $5(5)$ \\
\hline Miscellaneous lesions $^{\mathrm{a}}$ & $1(1)$ & $5(3)$ & & $6(4)$ \\
\hline Total & $56(50)$ & $33(21)$ & $1(1)$ & $90(72)$ \\
\hline
\end{tabular}

The numbers in brackets refer to patients who underwent successful PPVI

RVOT right ventricular outflow tract, ToF tetralogy of Fallot, $P A-V S D$ pulmonary atresia with ventricular septal defect, $D O R V$ double outlet right ventricle, TAC truncus arteriosus communis, $A O S T$ aortic valve stenosis, PST pulmonary valve stenosis, TGA transposition of the great arteries, VSD ventricular septal defect, $A V S D$ atrioventricular septal defect, PAiVS pulmonary atresia with intact ventricular septum

${ }^{a}$ Miscellaneous lesions include VSD and AVSD with PST, PAiVS

\begin{tabular}{llllll}
\hline Patient & Diagnosis & Status RVOT & CP, CC & CAA & RVOT size \\
\hline 1 & ToF & Conduit-free RVOT & LMC & No \\
2 & ToF & Conduit-free RVOT & LMC & No & \\
3 & ToF & Conduit-free RVOT & LAD & No \\
4 & ToF & Conduit-free RVOT & LAD & No & \\
5 & ToF & Homograft & LMC & No \\
6 & ToF & Homograft & LMC & No & \\
7 & PA-VSD & Homograft & RCA & No & \\
8 & ToF, absent pulmo- & Homograft & LMC & No & \\
& nary valve & & & & \\
9 & DORV & Conduit-free RVOT & LAD & No & Inadequate \\
10 & AVSD, PST & Conduit-free RVOT & LAD & No \\
11 & AOST, s.p. Ross & Homograft & LAD & No & Inadequate \\
12 & ToF & Conduit-free RVOT & LAD & No & Inadequate \\
13 & ToF & Conduit-free RVOT & LAD & No & \\
14 & VSD, PST & Conduit-free RVOT & LMC & No & Inadequate \\
15 & PA-VSD & Valveless conduit & LMC & LCA from RCA & Inadequate \\
16 & DORV & Conduit-free RVOT & - & LAD from RCA \\
17 & PST & Conduit-free RVOT & LAD & LAD from RCA & Inadequate \\
18 & ToF & Conduit-free RVOT & - & no &
\end{tabular}

RVOT right ventricular outflow tract, $C P / C C$ coronary artery proximity/compression, $C A A$ coronary artery anomaly, ToF tetralogy of Fallot, $P A-V S D$ pulmonary atresia with ventricular septal defect, $D O R V$ double outlet right ventricle, VSD ventricular septal defect, $P S T$ pulmonary valvular stenosis, AVSD atrioventricular septal defect, AOST aortic valve stenosis, $L M C$ left main coronary, $L A D$ left anterior descending coronary artery, $R C A$ right coronary artery the dimensions for placement of the Melody ${ }^{\mathrm{TM}}$ or SAPIEN valves available at that time (Table 2). CAAs were present in three of the 18 patients.

Seven patients $(8 \%)$ with anomalous origin of a major coronary artery branch were encountered in the entire cohort (Table 3). The diagnoses of these patients included tetralogy of Fallot, pulmonary atresia and ventricular septal defect (PA-VSD), double outlet right ventricle (DORV), and pulmonary valvular stenosis. All these patients underwent selective angiographies of both coronary arteries. Anomalous origin of the LAD from the right coronary artery or right aortic sinus crossing the RVOT (Figs. 1,2) was found 
Table 3 Patients with anomalous origin of a major coronary artery branch

\begin{tabular}{lllll}
\hline Patient & Diagnosis & Status RVOT & CAA & PPVI \\
\hline 1 & PA-VSD & Valveless conduit & LCA from RCA & PPVI aborted, CP/CC \\
2 & PST & Conduit-free native RVOT & LAD from RCA & PPVI aborted, inadequate RVOT, and CP \\
3 & DORV & Conduit-free RVOT & LAD from RCA & PPVI aborted, inadequate RVOT \\
4 & ToF & Contegra-conduit & LAD from RCA & Folded Melody \\
5 & PA-VSD & Homograft & LAD from RCA & Folded Melody \\
6 & ToF & Conduit-free RVOT & LAD from RCA & Edwards Sapien3 26 mm \\
7 & DORV & Valveless conduit and native RVOT & LAD from RCA & Melody both in conduit and in RVOT $^{\mathrm{TM}}$ \\
\hline
\end{tabular}

RVOT right ventricular outflow tract, CAA coronary artery anomaly, $P A$-VSD pulmonary atresia with ventricular septal defect, DORV double outlet right ventricle, $P S T$ pulmonary valve stenosis, $T o F$ tetralogy of Fallot, $L C A$ left anterior descending coronary artery, $R C A$ right coronary artery, $L A D$ left anterior descending coronary artery, $C P / C C$ coronary artery proximity/compression
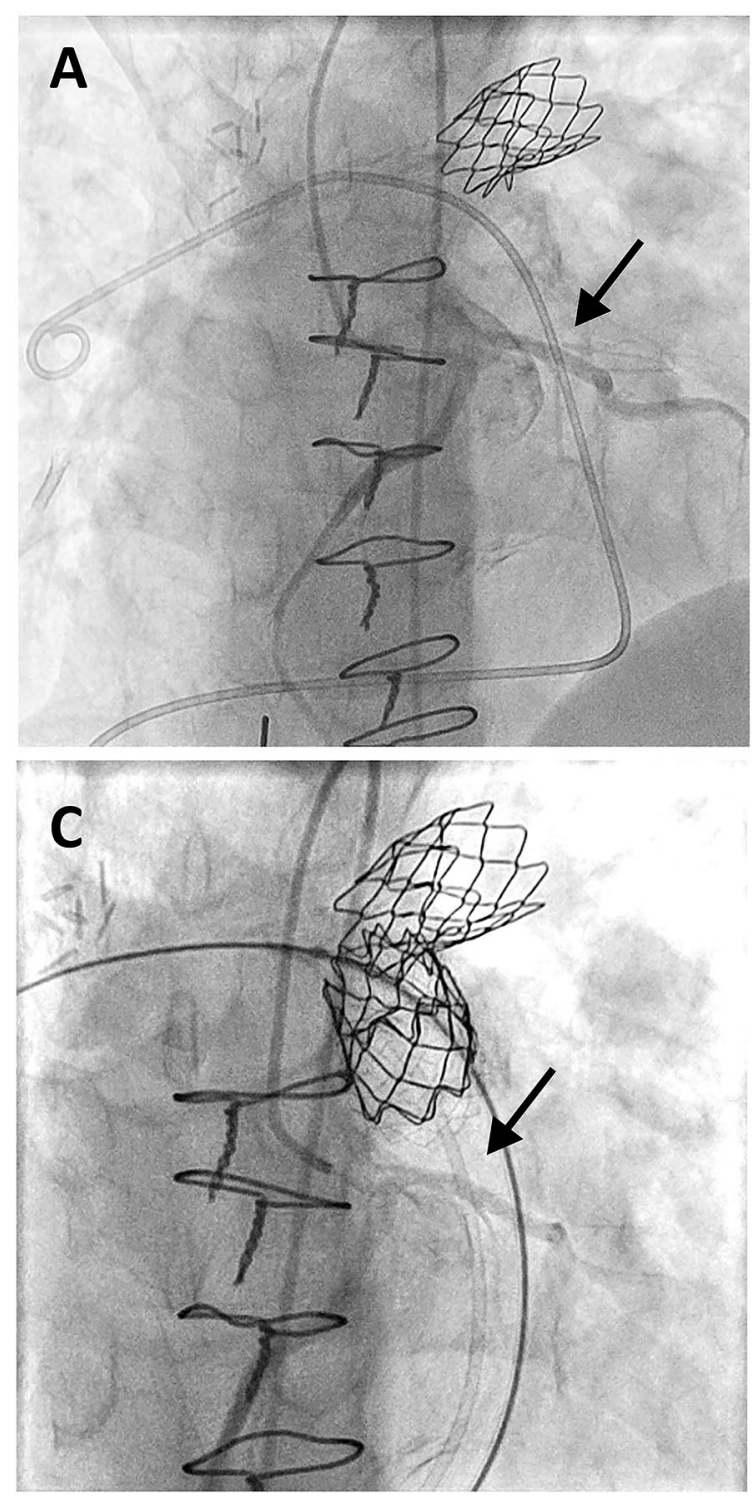

Fig. 1 Coronary angiography in pat. 5 (Table 3) shows origin of the RCA and LAD from the right coronary sinus (A). Angiography during placement of the stent in the landing zone confirms patency of the
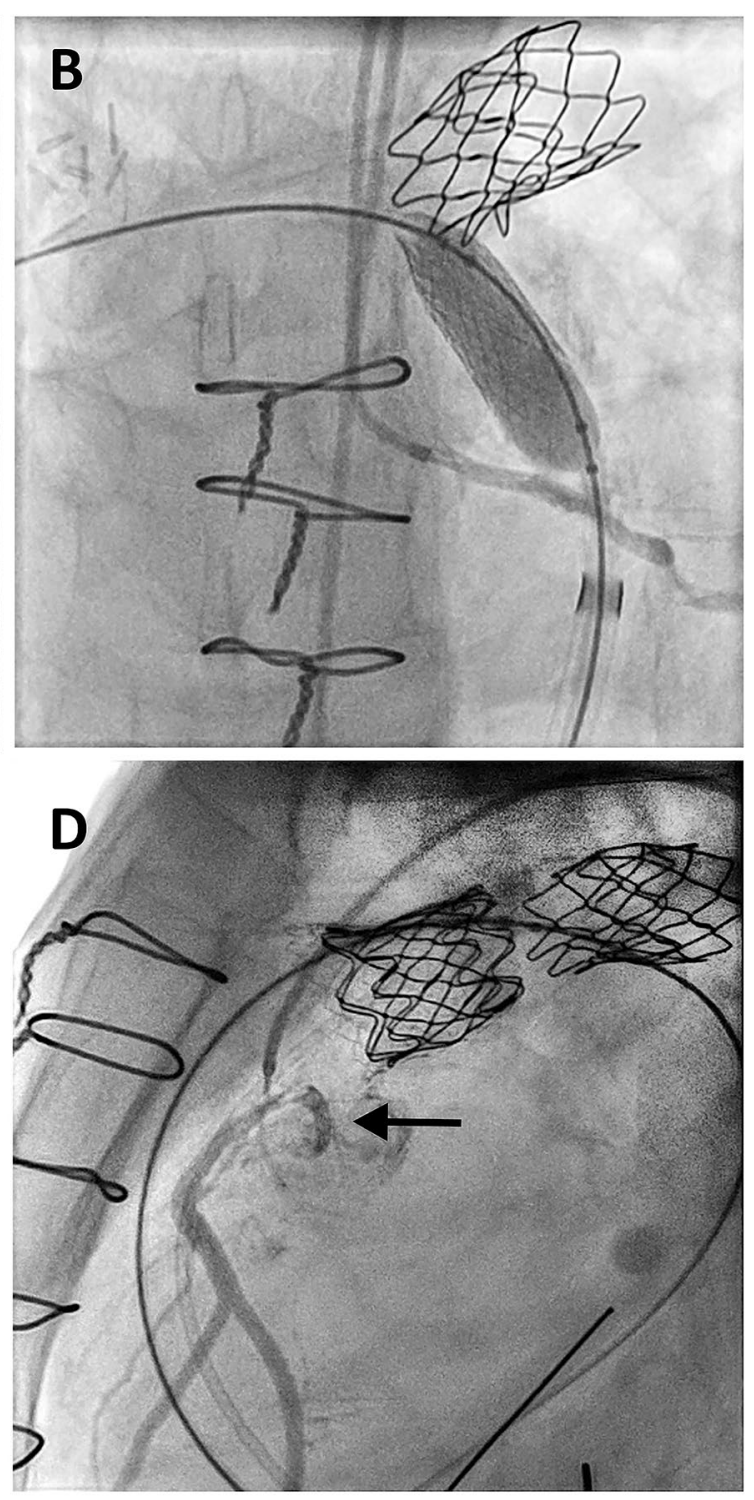

LAD (arrows) crossing the RVOT below (B). Final coronary angiography following placement of the folded Melody valve shows patent LAD (arrows) proximal to the valve $(\mathbf{C}, \mathbf{D})$ 

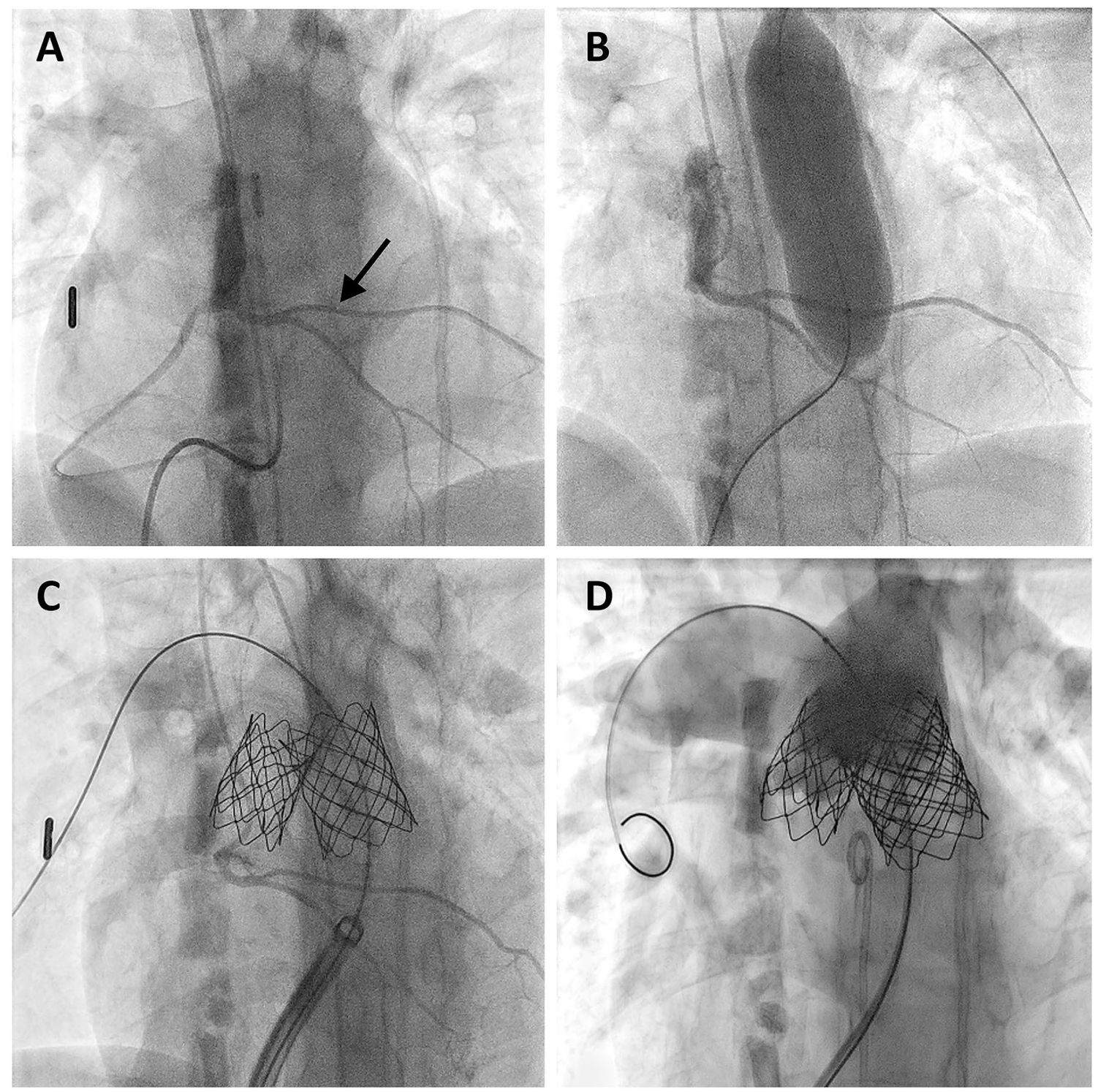

Fig. 2 Selective angiography of the right coronary artery in pat. 7 (Table 3) shows origin of the LAD (arrows) from the right coronary sinus crossing the RVOT (A). Selective angiography during balloon testing of the RVOT reveals that the LAD is located well below the expected landing zones both in the RVOT and in the PTFE conduit

in 6 patients. One additional patient had a single coronary artery originating from the right aortic sinus. In this patient the left coronary artery crossed posterior to the RVOT and underneath the pulmonary artery.

In three of these patients the decision was made not to attempt PPVI. In the patient with a single coronary artery the unfavorable course of the left coronary artery underneath the RVOT in close proximity to the expected landing zone prevented PPVI. In two patients with LAD originating from the right aortic sinus PPVI was not attempted due to stretched diameters of the intended landing zone of $31 \mathrm{~mm}$ and $28 \mathrm{~mm}$, respectively, and absent indentation of the fully

(B). Confirmation of coronary patency following placement of a Melody valve in the conduit and creation of a landing zone in the RVOT (C). Final pulmonary angiography shows good function of both valves

inflated balloon. Since the LAD crossed the outflow tract proximal to the expected position of an implanted valve, PPVI would have been theoretically possible in one of them. In the remaining patients the LAD crossed the RVOT at the level of the expected landing zone in close proximity to the fully expanded balloon (Table 3). In summary among 84 patients with adequate size conduits or RVOT only one patient was excluded from PPVI based on coronary artery proximity/compression due to a CAA.

PPVI was performed without complication in the remaining 4 patients with CAA (mean age $=26.8$ years, age range 17.4-32 years). The anatomy of the RVOT included $s / p$ 
implantation of $18 \mathrm{~mm}$ bovine internal jugular vein conduit (Contegra), s/p $22 \mathrm{~mm}$ homograft, and conduit-free RVOT following pulmonary valvotomy. The fourth patient had a valveless $18 \mathrm{~mm}$ PTFE RV-PA conduit in addition to the patent native RVOT.

Careful analysis of the angiograms in these patients revealed sufficient space for a safe landing zone distal to the LAD crossing the RVOT. All our patients underwent prestenting. In two patients a short landing zone proximal to the bifurcation limited prestenting to the implantation of a $8 \mathrm{Z}$ $22 \mathrm{~mm} \mathrm{CP}$ Stent $^{\mathrm{TM}}$ (NuMED Inc, Hopkinton, USA) and a 26 mm LD Max ${ }^{\mathrm{TM}}$ stent (ev3 Inc., Plymouth, USA), respectively (Table 3). A shortened Melody ${ }^{\mathrm{TM}}$ valve, achieved by folding of the proximal and distal struts, was implanted in both of these patients (Fig. 1). One of these patients and the applied technique have been published before [11]. The third patient was treated by implantation of a $26 \mathrm{~mm}$ SAPIEN 3 valve following prestenting with a $\mathrm{LD} \mathrm{Max}^{\mathrm{TM}}$ stent. The fourth patient underwent implantation of Melody ${ }^{\mathrm{TM}}$ valves both in the $18 \mathrm{~mm}$ PTFE conduit and into the native RVOT following prestenting with $26 \mathrm{~mm} \mathrm{LD} \mathrm{Max}^{\mathrm{TM}}$ and $8 \mathrm{Z} 45 \mathrm{~mm}$ covered CP stents, respectively (Fig. 2). In all patients selective angiographies following prestenting and after valve implantation revealed unimpeded flow to the coronary arteries (Figs. 1,2). The postinterventional course was uneventful and all patients are doing well with a mean follow-up of 3 years.

\section{Discussion}

Following repair of congenital heart defects a significant number of patients are left with long-term impairment of pulmonary valve function. To avoid the sequelae of longterm pulmonary regurgitation and/or residual pulmonary stenosis on right ventricular function PPVI has become the preferred treatment option for many of these patients [2-4]. Excellent results have been reported both with the Melody ${ }^{\mathrm{TM}}$ and with the SAPIEN valves $[4,12,13]$. According to the data based on 845 patients from the post-approval MELODY Registry, this treatment option is associated with a low risk of major complications (4.2\%) and a low incidence of procedure-related deaths $(0.5 \%)$ [4]. Recent data showed that PPVI with the Melody ${ }^{\mathrm{TM}}$ valve is offering excellent mediumand long-term results comparable to surgical valve replacement [14].

Proximity of a major coronary artery branch to the intended landing zone represents one of the main obstacles for successful PPVI $[5,7]$. The option of PPVI treatment was declined in 18/90 (20\%) of patients who underwent invasive testing. In 12 patients (13\%) this was due to possible interference with a coronary artery branch. In an additional 4 patients with RVOTs exceeding the size of presently available PPVI devices balloon interrogation revealed close proximity of a coronary artery branch to the expected landing zone. However, it should be noted that our cohort may be associated with some bias since some patients with unfavorably large RVOT diameters were referred for surgical intervention without invasive testing of the RVOT based on MRI findings (see also "Limitations of the Study").

Of specific interest are coronary artery anomalies associated with major coronary branches crossing the RVOT in close proximity to the potential landing zone $[5,7,15]$. Anatomic variations include major coronary artery branches originating either from the right or from the left aortic sinus. Seven patients $(8 \%)$ with coronary artery anomalies were identified in our study. The most frequent was anomalous origin of the LAD from the right coronary artery or right aortic sinus (six patients) while one patient presented with a single coronary artery originating from the right aortic sinus. Six of these patients had conotruncal malformations including tetralogy of Fallot, PA-VSD as well as DORV (Table 2). Our findings correspond with previous data describing coronary artery anomalies in patients with tetralogy of Fallot. Among 943 surgical patients with tetralogy of Fallot Pontailler et al. found $76(8 \%)$ with anomalous coronary arteries crossing the right ventricular infundibulum [8]. The most frequent anomalies were origin of the main or an accessory LAD from the right aortic sinus accounting for $62 \%$ of these anomalies. Major infundibular branches were present in about $20 \%$. Abnormal origin of the right coronary artery from the left aortic sinus or from the LAD was described in $12 \%$ while the remaining $6 \%$ represented patients with a single coronary originating either from the right or left aortic sinus [8]. Quite similar distributions of anatomic variants were reported by Ruzmetov et al. among 43 patients with tetralogy of Fallot and anomalous coronary arteries [9]. While these coronary anomalies no longer represent a significant risk factor for corrective surgery which frequently can be performed without the use of a right ventricular to pulmonary artery conduit, they remain important for the planning of later repeat surgery or PPVI $[8,9]$. Abnormal coronary artery anatomy was demonstrated in 34/226 (15\%) patients with tetralogy of Fallot who underwent catheterization and testing for intended PPVI [7]. In this and in other studies coronary artery anomalies were associated with an increased risk of coronary artery compression during balloon interrogation of the RVOT $[5,7,16]$. Despite this statistically increased risk the results of our study show that successful PPVI is possible in the majority of patients exhibiting a major coronary artery branch crossing the RVOT. The presence of these coronary artery anomalies should not be considered as a primary contraindication for PPVI.

In two of our patients with coronary artery anomaly and in 21/90 patients of our entire cohort successful valve implantation was achieved in conduit-free outflow tracts 
(Table 1). This confirms the experience of recent studies that percutaneous pulmonary valve replacement can be performed with low morbidity in patients with conduit-free RVOTs following pulmonary valvotomy, partial or complete pulmonary valvectomy, patch enlargement, or a combination of these [17-20]. New generations of self-expandable valve prostheses will soon become available for large RVOTs [3]. However, in patients with dysfunctional non-conduit RVOTs and requirement of large valve prostheses aortic root compression with the risk of aortic regurgitation or erosion of the aortic wall may represent a limiting factor [21].

Although the majority of the patients in our study had preceding 3D imaging for evaluation of the anatomy of the RVOT and coronary arteries the final decision for valve implantation was based on the results of angiographic imaging of the RVOT, balloon interrogation of the landing zone, and simultaneous imaging of the coronary arteries. Based on continuous improvements of 3D imaging techniques and introduction of image fusion techniques it can be expected that evaluation of the landing zone and its proximity to coronary artery branches will become even more accurate providing the possibility of exact pre-interventional planning and optimal deployment of the valve [16, 22-28].

\section{Limitations of the Study}

Limitations of our study are due to its retrospective nature and the relatively small sample size. Both the technique of balloon interrogation and the technique of coronary artery imaging experienced improvement during the elapsed period of the study. With regard to the proximity of major coronary artery branches to the expected landing zone we followed a rather conservative approach with the primary goal to minimize the risk of coronary artery compression. This may have reduced the rate of successful implantations but none of our patients experienced problems of coronary compression. Finally, we cannot exclude some selection bias of our cohort. While we did not reject patients because of anatomic variants of coronary artery origin including those associated with major branches crossing the RVOT, some patients with large RVOT beyond the range of percutaneous revalvulation underwent surgery without invasive testing of coronary artery proximity to the RVOT.

\section{Conclusion}

Coronary artery anomalies associated with a major coronary branch crossing the RVOT can be expected in about $8 \%$ of patients evaluated for PPVI. In our experience, these coronary anomalies frequently do not represent a contraindication for PPVI. Balloon testing revealed that the LAD frequently crosses the RVOT below the plane of the pulmonary valve and proximal to a potential landing zone. Since the landing zone may be rather short it may require implantation of a low profile pulmonary valve or application of the folded melody technique.

Acknowledgments A. Hanser and A. Hornung have received research grants from the "Stiftung zur Förderung der Erforschung der Zivilisationerkrankungen." A. Hanser reports grants from the Deutsche Herzstiftung e.V.

Author Contributions Study conception and design: $\mathrm{MH}$ and $\mathrm{AH}$; data collection and analysis: $\mathrm{MH}$ and $\mathrm{AH}$; clinical material preparation: $\mathrm{MH}, \mathrm{AH}, \mathrm{JM}, \mathrm{AHo}$, and LS. The first draft of the manuscript was written by $\mathrm{MH}$ and $\mathrm{AH}$ and all authors commented and contributed on it. All authors read and approved the final manuscript.

Funding Open Access funding enabled and organized by Projekt DEAL. The authors did not receive support from any organization for the submitted work.

Data Availability The datasets used and/or analyzed during the current study are available from the corresponding author on reasonable request.

Code Availability Data analysis was performed using SPSS; V. 25.0 Corp., NY, USA.

\section{Declarations}

Conflict of interest A. Hanser and A. Hornung have received research grants from the "Stiftung zur Förderung der Erforschung der Zivilisationerkrankungen." A. Hanser reports grants from the Deutsche Herzstiftung e.V. The other authors have no relevant financial or nonfinancial interests to disclose.

Ethical Approval This retrospective study was approved by the Ethics Committee at the Medical Faculty of the Eberhard Karls University and at the University Hospital Tuebingen (project number 307/2020BO2).

Consent to Participate Written consent was not required, as this is a retrospective data analysis. Date of registration 15/05/2020.

Consent for Publication The present paper is not under consideration elsewhere and has not been published elsewhere. All authors have read and approved the manuscript.

Open Access This article is licensed under a Creative Commons Attribution 4.0 International License, which permits use, sharing, adaptation, distribution and reproduction in any medium or format, as long as you give appropriate credit to the original author(s) and the source, provide a link to the Creative Commons licence, and indicate if changes were made. The images or other third party material in this article are included in the article's Creative Commons licence, unless indicated otherwise in a credit line to the material. If material is not included in the article's Creative Commons licence and your intended use is not permitted by statutory regulation or exceeds the permitted use, you will need to obtain permission directly from the copyright holder. To view a copy of this licence, visit http://creativecommons.org/licenses/by/4.0/. 


\section{References}

1. Cabalka AK, Hellenbrand WE, Eicken A, Kreutzer J, Gray RG, Bergersen L, Berger F, Armstrong AK, Cheatham JP, Zahn EM, McElhinney DB (2017) Relationships among conduit type, prestenting, and outcomes in patients undergoing transcatheter pulmonary valve replacement in the prospective North American and European melody valve trials. JACC Cardiovasc Interv 10:1746-1759

2. Cheatham JP, Hellenbrand WE, Zahn EM, Jones TK, Berman DP, Vincent JA, McElhinney DB (2015) Clinical and hemodynamic outcomes up to 7 years after transcatheter pulmonary valve replacement in the US melody valve investigational device exemption trial. Circulation 131:1960-1970

3. Giugno L, Faccini A, Carminati M (2020) Percutaneous pulmonary valve implantation. Korean Circ J 50:302-316

4. Nordmeyer J, Ewert P, Gewillig M, AlJufan M, Carminati M, Kretschmar O, Uebing A, Dahnert I, Rohle R, Schneider H, Witsenburg M, Benson L, Gitter R, Bokenkamp R, Mahadevan $\mathrm{V}$, Berger F (2019) Acute and midterm outcomes of the postapproval MELODY Registry: a multicentre registry of transcatheter pulmonary valve implantation. Eur Heart J 40:2255-2264

5. Fraisse A, Assaidi A, Mauri L, Malekzadeh-Milani S, Thambo JB, Bonnet D, Iserin L, Mancini J, Boudjemline Y (2014) Coronary artery compression during intention to treat right ventricle outflow with percutaneous pulmonary valve implantation: incidence, diagnosis, and outcome. Catheter Cardiovasc Interv 83:E260-268

6. Kostolny M, Tsang V, Nordmeyer J, Van Doorn C, Frigiola A, Khambadkone S, de Leval MR, Bonhoeffer P (2008) Rescue surgery following percutaneous pulmonary valve implantation. Eur J Cardiothorac Surg 33:607-612

7. Morray BH, McElhinney DB, Cheatham JP, Zahn EM, Berman DP, Sullivan PM, Lock JE, Jones TK (2013) Risk of coronary artery compression among patients referred for transcatheter pulmonary valve implantation: a multicenter experience. Circ Cardiovasc Interv 6:535-542

8. Pontailler M, Bernard C, Gaudin R, Moreau de Bellaing A, Mostefa Kara M, Haydar A, Barbanti C, Bonnet D, Vouhe P, Raisky O (2019) Tetralogy of Fallot and abnormal coronary artery: use of a prosthetic conduit is outdated. Eur J Cardiothorac Surg 56:94-100

9. Ruzmetov M, Jimenez MA, Pruitt A, Turrentine MW, Brown JW (2005) Repair of tetralogy of Fallot with anomalous coronary arteries coursing across the obstructed right ventricular outflow tract. Pediatr Cardiol 26:537-542

10. Hofbeck M, Kretschmar O, Sieverding L (2011) Bilateral percutaneous pulmonary valve implantation in dual conduits from the subpulmonary ventricle to the pulmonary arteries. Eur Heart $\mathbf{J}$ 32:2907

11. Jalal Z, Malekzadeh-Milani S, Hofbeck M, Al Najashi K, Thambo JB, Boudjemline Y (2015) A new percutaneous pulmonary valve implantation technique for complex right ventricular outflow tracts: the "folded melody valve." Catheter Cardiovasc Interv 85:604-610

12. Haas NA, Carere RG, Kretschmar O, Horlick E, Rodes-Cabau J, de Wolf D, Gewillig M, Mullen M, Lehner A, Deutsch C, Bramlage P, Ewert P (2018) Early outcomes of percutaneous pulmonary valve implantation using the Edwards SAPIEN XT transcatheter heart valve system. Int J Cardiol 250:86-91

13. Lehner A, Dashkalova T, Ulrich S, Fernandez Rodriguez S, Mandilaras G, Jakob A, Dalla-Pozza R, Fischer M, Schneider H, Tarusinov G, Kampmann C, Hofbeck M, Dahnert I, Kanaan M, Haas NA (2019) Intermediate outcomes of transcatheter pulmonary valve replacement with the Edwards Sapien 3 valve-German experience. Expert Rev Med Devices 16:829-834
14. Georgiev S, Ewert P, Eicken A, Hager A, Horer J, Cleuziou J, Meierhofer C, Tanase D (2020) Munich comparative study: prospective long-term outcome of the transcatheter melody valve versus surgical pulmonary bioprosthesis with up to 12 years of follow-up. Circ Cardiovasc Interv 13:e008963

15. Kapur S, Aeron G, Vojta CN (2015) Pictorial review of coronary anomalies in tetralogy of Fallot. J Cardiovasc Comput Tomogr 9:593-596

16. Rinaldi E, Sadeghi S, Rajpal S, Boe BA, Daniels C, Cheatham J, Sinha S, Levi DS, Aboulhosn J (2020) Utility of CT angiography for the prediction of coronary artery compression in patients undergoing transcatheter pulmonary valve replacement. World J Pediatr Congenit Heart Surg 11:295-303

17. Boshoff DE, Cools BL, Heying R, Troost E, Kefer J, Budts W, Gewillig M (2013) Off-label use of percutaneous pulmonary valved stents in the right ventricular outflow tract: time to rewrite the label? Catheter Cardiovasc Interv 81:987-995

18. Cools B, Brown SC, Heying R, Jansen K, Boshoff DE, Budts W, Gewillig M (2015) Percutaneous pulmonary valve implantation for free pulmonary regurgitation following conduit-free surgery of the right ventricular outflow tract. Int J Cardiol 186:129-135

19. Martin MH, Meadows J, McElhinney DB, Goldstein BH, Bergersen L, Qureshi AM, Shahanavaz S, Aboulhosn J, Berman D, Peng L, Gillespie M, Armstrong A, Weng C, Minich LL, Gray RG (2018) Safety and feasibility of melody transcatheter pulmonary valve replacement in the native right ventricular outflow tract: a multicenter pediatric heart network scholar study. JACC Cardiovasc Interv 11:1642-1650

20. Esmaeili A, Khalil M, Behnke-Hall K, Gonzalez YGMB, Kerst G, Fichtlscherer S, Akintuerk H, Schranz D (2019) Percutaneous pulmonary valve implantation (PPVI) in non-obstructive right ventricular outflow tract: limitations and mid-term outcomes. Transl Pediatr 8:107-113

21. Lindsay I, Aboulhosn J, Salem M, Levi D (2016) Aortic root compression during transcatheter pulmonary valve replacement. Catheter Cardiovasc Interv 88:814-821

22. Bosi GM, Capelli C, Khambadkone S, Taylor AM, Schievano S (2015) Patient-specific finite element models to support clinical decisions: a lesson learnt from a case study of percutaneous pulmonary valve implantation. Catheter Cardiovasc Interv 86:1120-1130

23. Caimi A, Sturla F, Pluchinotta FR, Giugno L, Secchi F, Votta E, Carminati M, Redaelli A (2018) Prediction of stenting related adverse events through patient-specific finite element modelling. J Biomech 79:135-146

24. Ebel S, Gottschling S, Buzan MTA, Grothoff M, Dahnert I, Wagner R, Grafe D, Lurz P, Gutberlet M, Lucke C (2019) 3D-assessment of RVOT dimensions prior percutaneous pulmonary valve implantation: comparison of contrast-enhanced magnetic resonance angiography versus $3 \mathrm{D}$ steady-state free precession sequence. Int J Cardiovasc Imaging 35:1453-1463

25. Goreczny S, Dryzek P, Moszura T, Lukaszewski M, Podgorski M, Nordmeyer S, Kuehne T, Berger F, Schubert S (2018) Magnetic resonance and computed tomography imaging fusion for live guidance of percutaneous pulmonary valve implantation. Postepy Kardiol Interwencyjnej 14:413-421

26. Malone L, Fonseca B, Fagan T, Gralla J, Wilson N, Vargas D, DiMaria M, Truong U, Browne LP (2017) Preprocedural risk assessment prior to PPVI with CMR and cardiac CT. Pediatr Cardiol 38:746-753

27. Pluchinotta FR, Sturla F, Caimi A, Giugno L, Chessa M, Giamberti A, Votta E, Redaelli A, Carminati M (2020) 3-Dimensional personalized planning for transcatheter pulmonary valve implantation in a dysfunctional right ventricular outflow tract. Int J Cardiol 309:33-39 
28. Tezza M, Witsenburg M, Nieman K, van de Woestijne PC, Budde RPJ (2019) Cardiac CT to assess the risk of coronary compression in patients evaluated for percutaneous pulmonary valve implantation. Eur J Radiol 110:88-96
Publisher's Note Springer Nature remains neutral with regard to jurisdictional claims in published maps and institutional affiliations. 